Check for updates

Cite this: J. Mater. Chem. A, 2019, 7, 23130

Received 19th July 2019

Accepted 15th September 2019

DOI: $10.1039 / \mathrm{c} 9 \mathrm{ta} 07835 \mathrm{e}$

rsc.li/materials-a

\section{Selective acid leaching: a simple way to engineer cobalt oxide nanostructures for the electrochemical oxygen evolution reaction $\uparrow$}

\begin{abstract}
Mingquan $\mathrm{Yu}^{\mathrm{a}}{ }^{\mathrm{K}}$ Kendra Solveig Belthle, ${ }^{\mathrm{a}}$ Cengiz Tüysüz ${ }^{\mathrm{b}}$ and Harun Tüysüz (DD *a
Developing a simple and cost-effective strategy to construct earth-abundant catalysts is in high demand for diverse applications. Herein, a general and facile strategy is developed to engineer cobalt oxide nanostructures via selective acid leaching for the electrochemical oxygen evolution reaction (OER). A leaching process is implemented to selectively remove $\mathrm{CoMoO}_{4}$ by treating mixed $\mathrm{Co}-\mathrm{Mo}$ oxides in diluted hydrochloric acid solution, resulting in the formation of sub-5 nm particles and a threefold increase in the specific surface area (up to $150 \mathrm{~m}^{2} \mathrm{~g}^{-1}$ ). The leached oxides exhibit superior OER activity to pristine oxides as a result of (i) a larger surface area, (ii) phase purification to expose more active $\mathrm{CO}_{3} \mathrm{O}_{4}$ species to the reactant, and (iii) faster charge transfer kinetics for the OER. This strategy can be also applied to a broader range of earth-abundant metals, where a second metal ( $\mathrm{Li}, \mathrm{Ca}$, and $\mathrm{Mg}$ ) is selectively leached out, which results in a material with a larger surface area and enhanced catalytic performance for the OER. Moreover, various metal oxides with a high surface area, such as $\mathrm{NiO}$ and $\mathrm{Fe}_{2} \mathrm{O}_{3}$, can be prepared via this simple synthetic method. This work will pave a new practical way for the production of high surface area catalysts for diverse applications.
\end{abstract}

\section{Introduction}

A high demand for renewable energy has arisen due to limited fossil fuel resources, which have been used as the main energy source and causing environmental issues. As a clean energy carrier that has the capacity to satisfy the global energy demand, hydrogen can be generated by electrochemical water splitting by utilizing solar energy without $\mathrm{CO}_{2}$ emission. ${ }^{1-4}$ The bottleneck of this technique for its commercialization lies on the anode side where oxygen is produced, namely the oxygen evolution reaction (OER). ${ }^{5,6}$ As OER possesses sluggish kinetics as a result of the formation of oxygen-oxygen bonds and four-electron transfer, an efficient catalyst is required to lower the overpotential and energy loss for the OER. ${ }^{6-9}$ The most efficient OER catalysts have been identified as $\mathrm{IrO}_{2}$ and $\mathrm{RuO}_{2}$, which are fabricated into thin films and employed in industrial proton exchange membrane water electrolyzers. ${ }^{7,10,11}$ However, these are not ideal catalysts as they suffer from lack of stability and durability under a high potential..$^{\mathbf{8} 12,13}$ Moreover, the scarcity and high cost of the noble metals (Ir and $\mathrm{Ru}$ ) make them impractical for large scale water electrolysis. Therefore, an urgent need for economic hydrogen production is to develop alternative catalysts, which are

${ }^{a}$ Max-Planck-Institut für Kohlenforschung, Kaiser-Wilhelm-Platz 1, Mülheim an der Ruhr, D-45470, Germany.E-mail: tueysuez@kofo.mpg.de

${ }^{b}$ Faculty of Education, Uşak University, Turkey

$\dagger$ Electronic supplementary information (ESI) available. See DOI: $10.1039 / \mathrm{c} 9 \mathrm{ta} 07835 \mathrm{e}$ composed of earth abundant-elements and catalyze the OER with high efficiency and long-term stability.

Over the past years, research has focused on studying firstrow (3d) transition metal-based catalysts to minimize the energy input for the OER..$^{\mathbf{6} 10,14,15}$ Accordingly, various categories of OER catalysts have been developed, including $3 \mathrm{~d}$ metal-based oxides, ${ }^{7,16,17}$ (oxy)hydroxides, ${ }^{17-21}$ phosphides, ${ }^{22-25}$ borates, ${ }^{26,27}$ and perovskites. ${ }^{28,29}$ Among these, $\mathrm{Co}_{3} \mathrm{O}_{4}$ has drawn particular interest not only due to its abundance and good catalytic performance, ${ }^{\mathbf{3 0}-33}$ but also because it can be easily constructed into desirable morphologies and shapes. ${ }^{34,35}$ There are diverse approaches to fabricate $\mathrm{Co}_{3} \mathrm{O}_{4}$ into nanostructures with a high specific surface area (SSA), which is a key parameter for escalating the reaction rate of the OER. ${ }^{\mathbf{3 0 , 3 4}}$ Esswein et al. prepared $\mathrm{Co}_{3} \mathrm{O}_{4}$ nanoparticles with average sizes of $5.9 \mathrm{~nm}, 21.1 \mathrm{~nm}$, and $46.9 \mathrm{~nm}$ through the hydrothermal method where the highest SSA and OER activities were obtained for the smallest nanoparticles. ${ }^{30}$ Nanocasting is a very effective method to fabricate well-defined nanostructures. Our group has utilized silica-based templates to prepare ordered mesoporous $\mathrm{Co}_{3} \mathrm{O}_{4}$ with a crystallite size of $\sim 8 \mathrm{~nm}$ and an SSA of $\sim 105 \mathrm{~m}^{2} \mathrm{~g}^{-1.4,36}$ Recently, laser technology has been employed to synthesize $\sim 5 \mathrm{~nm} \mathrm{Co}_{3} \mathrm{O}_{4}$ nanoparticles via ablation or fragmentation of a bulk cobalt precursor in a liquid solution. ${ }^{37,38}$ However, these methodologies are not practical since they suffer from (1) high production cost, (2) low yield, and (3) complicated procedures. To overcome these drawbacks, our group has designed a facile route using bio-waste templates to produce $\mathrm{Co}_{3} \mathrm{O}_{4}$ nanoparticles with large 
scalability. However, the bio-waste templated $\mathrm{Co}_{3} \mathrm{O}_{4}$ possessed an unsatisfactory SSA of $\sim 50 \mathrm{~m}^{2} \mathrm{~g}^{-1}$ and lower OER activity compared with ordered mesoporous $\mathrm{Co}_{3} \mathrm{O}_{4} \cdot{ }^{39}$ In this regard, it is desirable to develop an approach to engineer the $\mathrm{Co}_{3} \mathrm{O}_{4}$ nanostructure to enhance the SSA which can provide a larger number of catalytically active centers.

In this study, we reported a simple selective acid leaching strategy to engineer the $\mathrm{Co}_{3} \mathrm{O}_{4}$ nanostructures for electrochemical water oxidation. Through a coffee-waste $(\mathrm{CW})$ templating method by following a simple impregnation-calcination process, ${ }^{39}$ mesoporous Co-Mo oxides were prepared with a mixed crystal phase of $\mathrm{Co}_{3} \mathrm{O}_{4}$ and $\mathrm{CoMoO}_{4}$. With post-treatment, the $\mathrm{CoMoO}_{4}$ phase was selectively removed by using diluted $\mathrm{HCl}$ solution, which leads to the formation of sub-5 $\mathrm{nm} \mathrm{Co} \mathrm{O}_{4}$ nanoparticles and more than threefold enhancement of the SSA, up to $150 \mathrm{~m}^{2} \mathrm{~g}^{-1}$. The leached oxides exhibited enhanced OER activity due to a larger SSA and more active $\mathrm{Co}_{3} \mathrm{O}_{4}$ species which were exposed to the reactant. Additionally, we demonstrated that this leaching strategy can be also applied to selectively remove other earth-abundant metals from mixed Co-M oxides ( $\mathrm{M}=\mathrm{Li}, \mathrm{Ca}$, and $\mathrm{Mg}$ ). The developed method is versatile and can be also applied to prepare nanoscale $\mathrm{Fe}_{2} \mathrm{O}_{3}$ and $\mathrm{NiO}$ with high surface areas.

\section{Experimental section}

\subsection{Synthesis of coffee-waste templated metal oxides}

Coffee-waste templated metal oxides were prepared through a simple impregnation-calcination procedure. ${ }^{39} \mathrm{Co}\left(\mathrm{NO}_{3}\right)_{2} \cdot 6 \mathrm{H}_{2} \mathrm{O}$ ( $>98 \%$, Honeywell Fluka) and $\mathrm{H}_{3}\left(\mathrm{P}\left(\mathrm{Mo}_{3} \mathrm{O}_{10}\right)_{4}\right) \cdot \mathrm{H}_{2} \mathrm{O}$ (ACS reagent, Aldrich) were used as metal precursors in this study, with a designed Co/Mo ratio (2/1, 4/1, 8/1 and 16/1) well mixed for the synthesis of Co-Mo oxides. Coffee waste (TIZIO Premium Caffè) was collected from the tray of a coffee machine and washed with hot water until it became colorless, and afterwards was used as the template. The weight ratio of the coffee waste template to metal precursors was maintained at 2/1. For a small batch, $4 \mathrm{~g}$ of pre-washed coffee waste was added to the metal precursor solution for impregnation, whereas $20 \mathrm{~g}$ of pre-washed coffee waste was used as the template for large batch synthesis of $\mathrm{Co}_{4} \mathrm{Mo}$ oxides. After drying, the composite materials were calcined at 400 ${ }^{\circ} \mathrm{C}$ for $4 \mathrm{~h}$ with a ramping rate of $2{ }^{\circ} \mathrm{C}$ min under air.

To prepare $\mathrm{Co}_{4} \mathrm{M}$ oxides $(\mathrm{M}=\mathrm{Li}, \mathrm{Mg}$, and $\mathrm{Ca}), \mathrm{LiNO}_{3}(>95 \%$, Riedel-de Haën), $\mathrm{Mg}\left(\mathrm{NO}_{3}\right)_{2} \cdot 6 \mathrm{H}_{2} \mathrm{O}(>99 \%$, Honeywell Fluka), and $\mathrm{Ca}\left(\mathrm{NO}_{3}\right)_{2} \cdot 6 \mathrm{H}_{2} \mathrm{O}(>99 \%$, Alfa Aesar) were used as precursors and mixed with $\mathrm{Co}\left(\mathrm{NO}_{3}\right)_{2} \cdot 6 \mathrm{H}_{2} \mathrm{O}$ with a Co/M ratio of $4 / 1$, followed by impregnation into $4 \mathrm{~g}$ of pre-washed coffee and the same calcination step.

For the synthesis of $\mathrm{Ni}_{4} \mathrm{Ca}$ oxides and $\mathrm{Fe}_{4} \mathrm{Ca}$ oxides, $\mathrm{Ni}\left(\mathrm{NO}_{3}\right)_{2} \cdot 6 \mathrm{H}_{2} \mathrm{O}(>98 \%$, Sigma-Aldrich $)$ and $\mathrm{Fe}\left(\mathrm{NO}_{3}\right)_{3} \cdot 9 \mathrm{H}_{2} \mathrm{O}$ $(>98 \%$, Sigma-Aldrich) were used as precursors and mixed with $\mathrm{Ca}\left(\mathrm{NO}_{3}\right)_{2} \cdot 6 \mathrm{H}_{2} \mathrm{O}$ with a $\mathrm{M} / \mathrm{Ca}$ ratio of $4 / 1$, followed by the same impregnation and calcination steps.

\subsection{Leaching process}

Concentrated $\mathrm{HCl}$ solution (37-38\%, J. T. Baker) was diluted with distilled water to prepare leaching solutions of various concentrations ( $0.01 \mathrm{M}, 0.05 \mathrm{M}, 0.1 \mathrm{M}$ and $0.2 \mathrm{M})$. The powder samples were then added to the diluted acid solution and kept shaking at a speed of $480 \mathrm{rpm}$ for a certain period of time (5 min, $30 \mathrm{~min}, 2 \mathrm{~h}$ and $6 \mathrm{~h}$ ). Afterwards, the leached oxides were collected by centrifugation and washed with water, followed by drying in air at $80^{\circ} \mathrm{C}$ overnight.

\subsection{Characterization}

Powder X-ray diffraction (XRD) patterns were collected at room temperature on a Stoe theta/theta diffractometer in BraggBrentano geometry using $\mathrm{Cu} \mathrm{K} \mathrm{K} \alpha_{1 / 2}$ radiation. Transmission electron microscopy (TEM) images of the samples were captured at $100 \mathrm{kV}$ using an $\mathrm{H}-7100$ electron microscope from Hitachi. High resolution TEM (HR-TEM) and scanning TEM (STEM) images were taken on HF-2000 and Hitachi S-5500 microscopes, respectively. SEM-EDX measurements were performed using a Hitachi S-3500N electron microscope. $\mathrm{N}_{2}$-sorption isotherms were measured using a 3Flex Micrometrics at 77 K. Prior to the measurements, the samples were degassed under vacuum at a temperature of $150{ }^{\circ} \mathrm{C}$ for $10 \mathrm{~h}$. Brunauer-EmmettTeller (BET) surface areas were determined in the relative pressure range between 0.06 and 0.2. X-ray photoelectron spectroscopy (XPS) measurements were carried out with a SPECS GmbH spectrometer with a hemispherical analyzer (PHOIBOS 150 1D-DLD). The monochromatic Al K $\alpha$ X-ray source $(E=1486.6 \mathrm{eV})$ was operated at $100 \mathrm{~W}$. An analyzer pass energy of $20 \mathrm{eV}$ was applied for the narrow scans. The medium area mode was used as the lens mode. The base pressure during the experiment in the analysis chamber was $5 \times 10^{-10} \mathrm{mbar}$. The binding energy scale was corrected for surface charging by using the $\mathrm{C} 1 \mathrm{~s}$ peak of contaminant carbon as the reference at $284.5 \mathrm{eV}$.

\subsection{Electrochemical measurements}

Electrochemical measurements were carried out in a typical three-electrode configuration using a rotating disc electrode (Model: AFMSRCE, PINE Research Instrumentation), and a hydrogen reference electrode (HydroFlex, Gaskatel) and Pt wire were used as the reference electrode and counter electrode, respectively. $1 \mathrm{M} \mathrm{KOH} \mathrm{(85 \% ,} \mathrm{VWR} \mathrm{Chemicals)} \mathrm{solution} \mathrm{was} \mathrm{fil-}$ led in a Teflon cell as the electrolyte. Argon was continuously purged through the cell to remove oxygen during the measurement. The temperature of the electrolyte was kept at 25 ${ }^{\circ} \mathrm{C}$ using a water circulation system. Working electrodes were fabricated by depositing catalysts on the center circle of glass carbon (GC) electrodes (PINE, $5 \mathrm{~mm}$ diameter, $0.196 \mathrm{~cm}^{2}$ area). Before depositing materials, the surface of each GC electrode was polished with an $\mathrm{Al}_{2} \mathrm{O}_{3}$ suspension (1.0 and $0.05 \mu \mathrm{m}$, Allied High Tech Products, Inc.) and thoroughly cleaned with distilled water by sonication for $5 \mathrm{~min}$. To prepare the catalyst ink, 4.8 $\mathrm{mg}$ of the catalyst powder was dispersed in a mixed solution containing $0.75 \mathrm{~mL}$ of $\mathrm{H}_{2} \mathrm{O}, 0.25 \mathrm{~mL}$ of 2-propanol and $50 \mu \mathrm{L}$ of Nafion (5\% in a mixture of water and alcohol). Then the solution mixture was put in a sonication bath for $30 \mathrm{~min}$ to disperse the solid catalyst in the solution. After that, $5.25 \mu \mathrm{L}$ of the catalyst ink was dropped onto the GC electrode (catalyst 
loading, $0.12 \mathrm{mg} \mathrm{cm}^{-2}$ ) and dried under light irradiation for 10 min. The GC electrode was then connected to the rotating disc electrode for OER measurements.

Linear sweep voltammetry (LSV) curves were measured by sweeping the potential from $0.7 \mathrm{~V}$ to $1.7 \mathrm{~V} v s$. RHE with a scan rate of $10 \mathrm{mV} \mathrm{s}^{-1}$. Cyclic voltammetry $(\mathrm{CV})$ measurements were carried out in a potential range between 0.7 and $1.6 v s$. RHE with a scan rate of $50 \mathrm{mV} \mathrm{s}{ }^{-1}$. Impedance spectra were measured at an anodic potential of $1.6 \mathrm{~V} v s$. RHE, and the spectra were collected from $10^{5} \mathrm{~Hz}$ to $0.1 \mathrm{~Hz}$ with an amplitude of $5 \mathrm{mV}$. The electrochemical active surface area (ECSA) was estimated by measuring the capacitive current in a non-faradaic region. Briefly, $\mathrm{CV}$ with increasing scan rates ranging from 20 to $180 \mathrm{mV} \mathrm{s}^{-1}$ was performed in the potential window from 1.2 to $1.3 \mathrm{~V} v$ s. RHE. By plotting the capacitive current against the scan rate, the double layer capacitance $\left(C_{\mathrm{dl}}\right)$ is obtained as half of the slope and the ECSA can be derived from the equation ECSA = $C_{\mathrm{dl}} / C_{\mathrm{s}}$, where $C_{\mathrm{s}}$ is the specific capacitance and its value is chosen as $0.04 \mathrm{mF} \mathrm{cm}^{-2}$ in alkaline solution. ${ }^{10}$ To perform the long-term stability test, an electrode was fabricated by dropcasting the catalyst ink onto the surface of carbon fiber paper $\left(0.5 \times 1 \mathrm{~cm}^{2}\right)$ as well, where the catalyst loading was kept at 0.5 $\mathrm{mg} \mathrm{cm}{ }^{-2}$. A chronopotentiometric test was performed by using controlled current electrolysis at a constant current density of $10 \mathrm{~mA} \mathrm{~cm}{ }^{-2}$. In all measurements, the IR drop was compensated at $85 \%$, and a rotating disc electrode configuration was maintained at a rotation speed of $2000 \mathrm{rpm}$ for the measurements of GC electrodes.

\section{Results and discussion}

As illustrated in the scheme (Fig. 1a), the process of fabricating ultra-small $\mathrm{Co}_{3} \mathrm{O}_{4}$ nanoparticles can be divided into two steps. The first step is to synthesize mesoporous Co-Mo oxides through a hard-templating method by using coffee-waste grounds as a sustainable template. ${ }^{39}$ Briefly, CW templates were impregnated with an aqueous solution containing the desired ratio of metal precursors, followed by calcination/combustion to remove the carbon-based template. Before the combustion of the carbon based template, metal precursors are converted to crystallize the mixed oxides, i.e. $\mathrm{Co}_{3} \mathrm{O}_{4}$ and $\mathrm{CoMoO}_{4}$.

Transition-metal molybdates can possess three different monoclinic structures $(\alpha, \beta$, and $\gamma$ ) depending on the synthetic conditions. The $\gamma$-CoMoO -type structure appears at high pressure (above $60 \mathrm{kbar}$ ) and crystallizes into a relatively dense structure. On the other hand, experimentally observed $\mathrm{CoMoO}_{4}$ generally has $\alpha$ - and $\beta$-phases, which have a more open structure on the basis of defective cubic close-packing of oxygen atoms. $^{40,41} \beta$ to $\alpha$ phase transition is observed at elevated temperatures (above $700{ }^{\circ} \mathrm{C}$ ). ${ }^{\mathbf{4 0 , 4 1}}$ The low-temperature form, i.e. the $\beta-\mathrm{CoMoO}_{4}$ phase, has a crystal structure where $\mathrm{Co}^{2+}$ and $\mathrm{Mo}^{6+}$ cations are located in distorted octahedral and tetrahedral sites, respectively, which makes it unstable under harsh conditions. ${ }^{\mathbf{4 1 4 2}}$ Thus, an acid-driven leaching process can be applied to remove the cobalt molybdenum oxide phase selectively. For this, a leaching process was carried out by immersing the cobalt molybdenum oxide powders in diluted $\mathrm{HCl}$ solution at room temperature. The $\mathrm{CoMoO}_{4}$ phase, which should be a $\beta$ phase after calcination at $400{ }^{\circ} \mathrm{C}$, was selectively leached out in an acid environment. We attribute the leaching to the open and disordered structure of $\beta-\mathrm{CoMoO}_{4}$ that is not stable in the presence of acid, where the defective oxygen sites are easily coupled with protons leading to the dissolution of the $\mathrm{CoMoO}_{4}$ phase, whereas $\mathrm{Co}_{3} \mathrm{O}_{4}$ with a compact spinel structure is more resistant to acid corrosion. ${ }^{43}$

$\mathrm{X}$-ray diffraction (XRD) analysis was first conducted to study the leaching effect on the composition of cobalt molybdenum mixed oxides with Co/Mo ratios of 16, 8, 4, and 2. As shown in the XRD patterns of pristine oxides (Fig. 1b), distinct reflections at $2 \theta=19.0^{\circ}, 31.3^{\circ}, 36.8^{\circ}$, and $44.8^{\circ}$ are exhibited on CWtemplated $\mathrm{Co}_{3} \mathrm{O}_{4}$, representing the (111), (220), (311), and (400) facets of the $\mathrm{Co}_{3} \mathrm{O}_{4}$ spinel structure. Due to the much larger radius of the Mo cation compared to the Co cation, the incorporation of Mo into the $\mathrm{Co}_{3} \mathrm{O}_{4}$ spinel via substituting tetrahedral $\mathrm{Co}^{2+}$ or octahedral $\mathrm{Co}^{3+}$ is unlikely. Thus, a second crystal phase of $\mathrm{CoMoO}_{4}$ appeared with the incorporation of Mo into the mixed oxides. The emerged diffraction peaks at $2 \theta=23.3^{\circ}$ and $26.5^{\circ}$ corresponded to the (021) and (002) planes of $\beta$ $\mathrm{CoMoO}_{4}$, respectively. ${ }^{41}$ It is worth noting that the diffraction peaks of the $\mathrm{CoMoO}_{4}$ phase are sharper than those of the $\mathrm{Co}_{3} \mathrm{O}_{4}$ phase, suggesting that $\mathrm{CoMoO}_{4}$ crystalized into larger crystallites. This should be related to a higher decomposition temperature of the Mo precursor (phosphomolybdic acid) compared to that of the Co precursor (cobalt nitrate). It has been reported that the decomposition of phosphomolybdic acid occurs at a temperature above $400{ }^{\circ} \mathrm{C},{ }^{\mathbf{4 4 , 4 5}}$ while cobalt nitrate could be completely decomposed into $\mathrm{Co}_{3} \mathrm{O}_{4}$ at 210 ${ }^{\circ} \mathrm{C} .{ }^{46}$ As a result, phosphomolybdic acid was decomposed at high temperature and crystallized with $\mathrm{Co}_{3} \mathrm{O}_{4}$ into larger $\mathrm{CoMoO}_{4}$ crystals. In the case of the mixed oxides with the lowest Mo ratio (Co/Mo 16/1), the XRD patterns displayed reflections at the same angles as those of pure $\mathrm{Co}_{3} \mathrm{O}_{4}$, where no additional reflections were observed belonging to $\mathrm{CoMoO}_{4}$. We attribute this to a small amount of $\mathrm{CoMoO}_{4}$ that was not detected by XRD. Upon a leaching process in $0.1 \mathrm{M} \mathrm{HCl}$ solution for $2 \mathrm{~h}$, all the mixed oxides exhibited a pure $\mathrm{Co}_{3} \mathrm{O}_{4}$ spinel phase (Fig. 1c), which endorses selective leaching of the $\mathrm{CoMoO}_{4}$ phase.

To further confirm the selective leaching of Mo species, elemental compositions of all the oxides were determined by energy-dispersive X-ray spectroscopy (EDX) before and after the leaching process, and the results are summarized in Fig. S1-S3 and Tables S1, S2. $\dagger$ The actual ratio of $\mathrm{Co} / \mathrm{Mo}$ in the mixed oxides was relatively well-matched with the stoichiometry of Co and Mo precursors, as shown in Fig. S2 and Table S1. $\dagger$ For the leached mixed oxides, dramatic loss of Mo was determined after acid-leaching, leading to a significantly higher ratio of $\mathrm{Co} / \mathrm{Mo}$. This confirms that Mo species were selectively removed under the acidic conditions (Fig. S3 and Table S2 $\dagger$ ), which is in line with the XRD measurements. Moreover, this acid leaching process was able to wash out most impurities from the coffee waste grounds (Tables S1 and S2 $\dagger$ ). This is crucial for determining the catalytic performance of the oxides as it helps minimize the effect from impurities. 
a
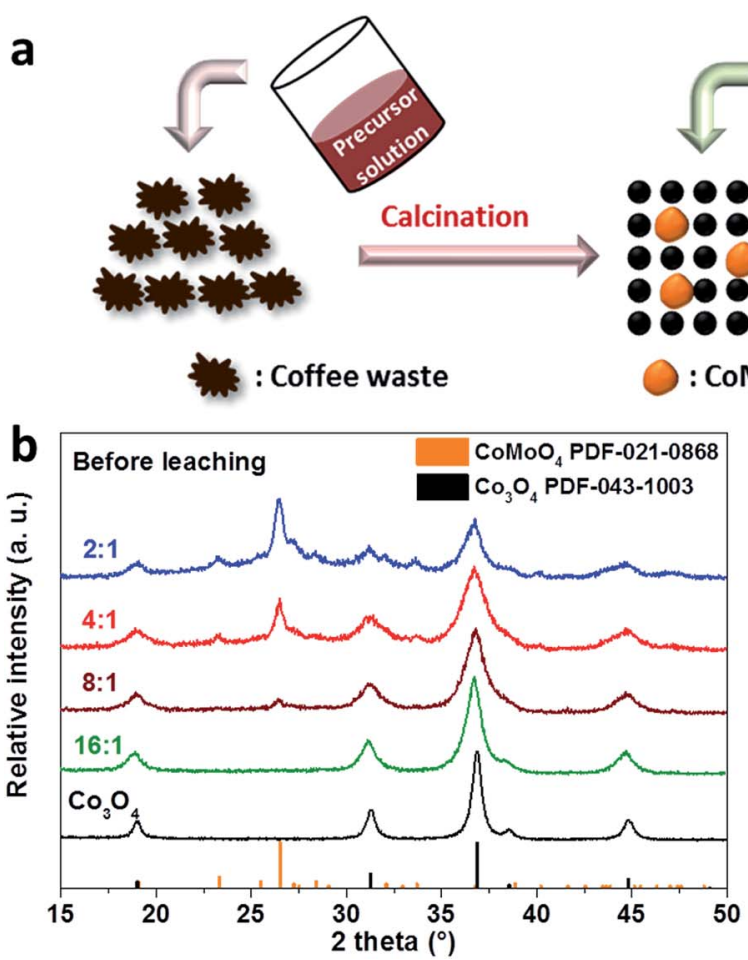
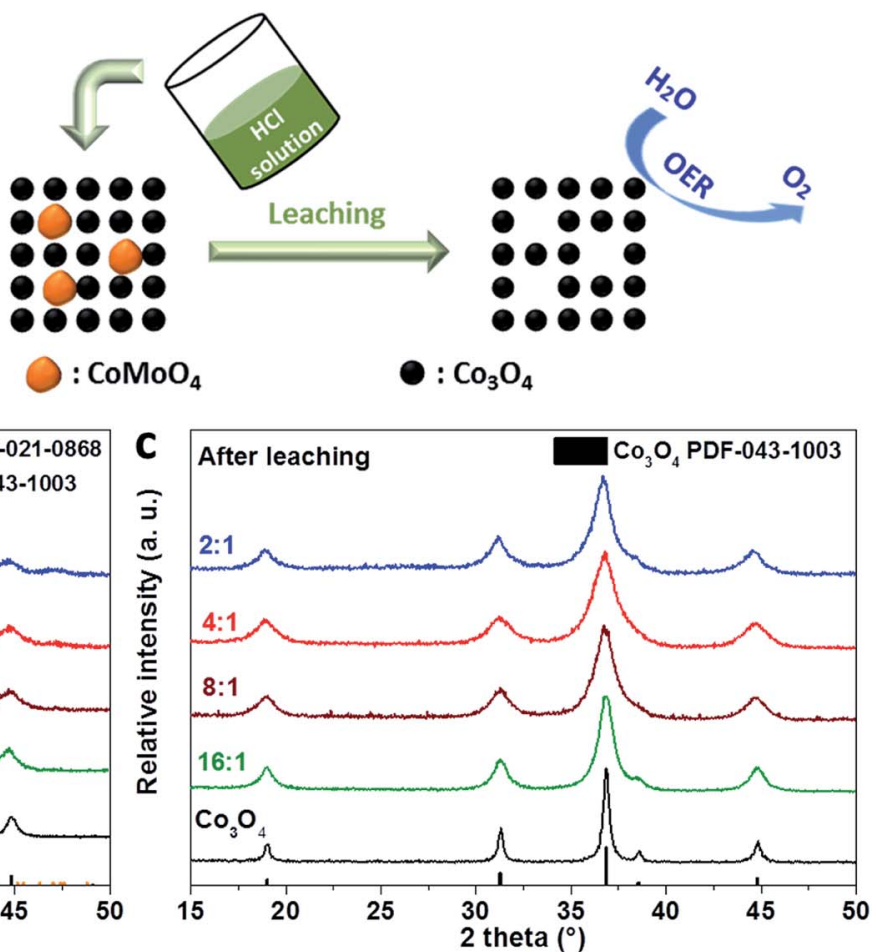

Fig. 1 (a) Schematic illustration of the acid-leaching process to engineer the structure of CW-templated Co-Mo oxides for the electrocatalytic OER. Wide-angle XRD patterns of $\mathrm{CW}$-templated $\mathrm{Co}-\mathrm{Mo}$ oxides and $\mathrm{CO}_{3} \mathrm{O}_{4}$ before (b) and after (c) leaching in $0.1 \mathrm{M} \mathrm{HCl} \mathrm{solution} \mathrm{for} 2 \mathrm{~h}$.

After confirming the selective leaching of Mo by structural and elemental analyses, its effect on the textural parameters was evaluated by $\mathrm{N}_{2}$ physisorption measurements. The specific surface areas (SSAs) were calculated from the adsorption isotherms via the Brunauer-Emmett-Teller (BET) method. As shown in Fig. S4, $\dagger$ a typical type IV isotherm for mesoporous materials was observed for all the Co-Mo oxides before and after the acid leaching process. Fig. 2 summarizes the calculated BET surface areas of oxides before and after the leaching process.

The pristine oxides with various Mo contents showed a similar SSA in the range of $36-55 \mathrm{~m}^{2} \mathrm{~g}^{-1}$ (Table S1 $\dagger$ ). A slight decrease of SSAs was observed with increasing Mo amount where the lowest SSA $\left(36 \mathrm{~m}^{2} \mathrm{~g}^{-1}\right)$ was obtained for $\mathrm{Co}_{2} \mathrm{Mo}$ oxides. This can be ascribed to the larger particle size of $\mathrm{CoMoO}_{4}$ as observed from the XRD patterns. After acid leaching and selective removal of $\mathrm{CoMoO}_{4}$, SSAs of leached oxides increased significantly. In addition to a higher SSA, selective removal of $\mathrm{CoMoO}_{4}$ also creates more porosity within the framework of particles, which can be seen from the increased pore volume of the mixed oxides after leaching (Tables S1 and $\mathrm{S} 2 \dagger)$. Comparing the increase of SSAs between leached and unleached oxides, the higher designed ratio of Mo leads to a more pronounced increase of SSAs (up to 3.3 fold) as a result of acid leaching (Fig. 2). Among them, acid-leached $\mathrm{Co}_{4} \mathrm{Mo}$ oxides showed the highest SSA of $150 \mathrm{~m}^{2} \mathrm{~g}^{-1}$, significantly higher than that of ordered mesoporous $\mathrm{Co}_{3} \mathrm{O}_{4}\left(\sim 105 \mathrm{~m}^{2} \mathrm{~g}^{-1}\right)$ which is replicated from ordered mesoporous silica. ${ }^{4}$

Electron microscopy measurements were further conducted to characterize the morphology and structure of the samples. As

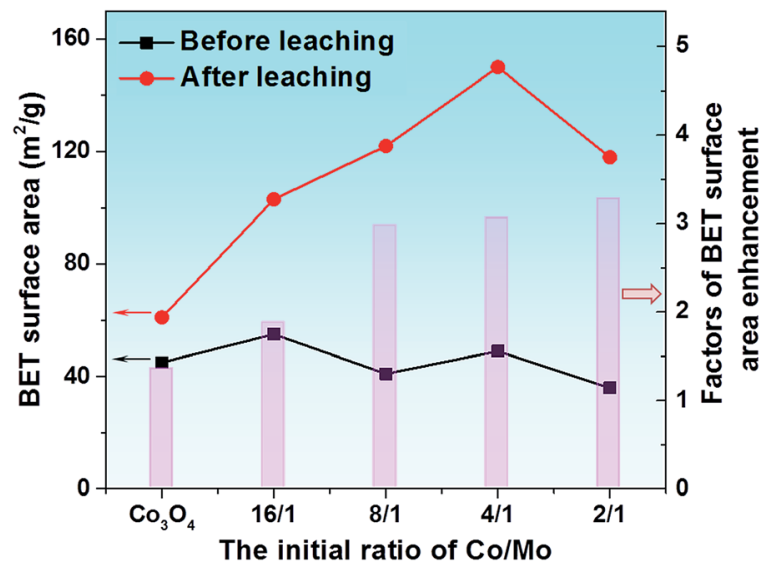

Fig. 2 Summarized values of the BET surface area (left axis) and incremental factors on the BET surface area (right axis) of CW-templated $\mathrm{Co}-\mathrm{Mo}$ oxides and $\mathrm{CO}_{3} \mathrm{O}_{4}$ before and after leaching in $0.1 \mathrm{M}$ $\mathrm{HCl}$ solution for $2 \mathrm{~h}$.

shown in the transmission electron microscopy (TEM) images (Fig. S5 $\dagger$ ), a typical structure consisting of nano-sized crystals was observed for both pristine and acid-leached $\mathrm{Co}_{3} \mathrm{O}_{4}$. For the selected $\mathrm{Co}_{4} \mathrm{Mo}$ oxide sample, the average particle size was around $6 \mathrm{~nm}$, and after acid leaching, this was reduced to below $5 \mathrm{~nm}$ (Fig. 3a and e). A closer examination of these particles before acid leaching displays clear crystal planes with a spacing of 0.23 and $0.21 \mathrm{~nm}$ (Fig. 3b), corresponding to the (311) and (400) lattices of the $\mathrm{Co}_{3} \mathrm{O}_{4}$ spinel, respectively. 
Additionally, much larger particles were also found in this pristine $\mathrm{Co}_{4} \mathrm{Mo}$ oxide (yellow circles in Fig. $3 \mathrm{~b}$ ). The larger particles isolated from small $\mathrm{Co}_{3} \mathrm{O}_{4}$ particles (Fig. $\mathrm{S} 6 \dagger$ ) and the lattices fringes with a spacing of $0.34 \mathrm{~nm}$ can be indexed to the (002) planes of $\mathrm{CoMoO}_{4}$. The formation of both small $\mathrm{Co}_{3} \mathrm{O}_{4}$ and large $\mathrm{CoMoO}_{4}$ particles was observed in the scanning electron microscopy (SEM) image of the pristine $\mathrm{Co}_{4} \mathrm{Mo}$ oxide (Fig. 3c), where large $\mathrm{CoMoO}_{4}$ particles were integrated with the matrix of small $\mathrm{Co}_{3} \mathrm{O}_{4}$ particles. In Fig. 3d, the SEM-energy dispersive Xray spectroscopy (EDX) mapping images show a uniform distribution of $\mathrm{Co}$ and $\mathrm{O}$ elements, while the Mo element was concentrated on the large particles of $\mathrm{CoMoO}_{4}$. Furthermore, EDX analysis was conducted on representative locations to examine the elemental composition. As seen in Fig. S7, $\dagger$ less than 2 at\% Mo was detected in the area mostly consisting of $\mathrm{Co}_{3} \mathrm{O}_{4}$ particles, whereas a much higher amount of Mo was detected in the area where larger $\mathrm{CoMoO}_{4}$ particles are present. These results illustrate a consolidation of smaller $\mathrm{Co}_{3} \mathrm{O}_{4}$ and larger $\mathrm{CoMoO}_{4}$ particles within the pristine mixed oxide, which is well consistent with the XRD analysis.

Upon the removal of $\mathrm{CoMoO}_{4}$ by acid leaching, two changes were observed from the high-resolution TEM and SEM images of $\mathrm{Co}_{4} \mathrm{Mo}$ oxides (Fig. 3e-g). The large $\mathrm{CoMoO}_{4}$ particles were not observed throughout the sample; instead, a uniform structure with interconnected ultra-small nanoparticles was obtained. Characteristic lattice planes of the $\mathrm{Co}_{3} \mathrm{O}_{4}$ spinel were

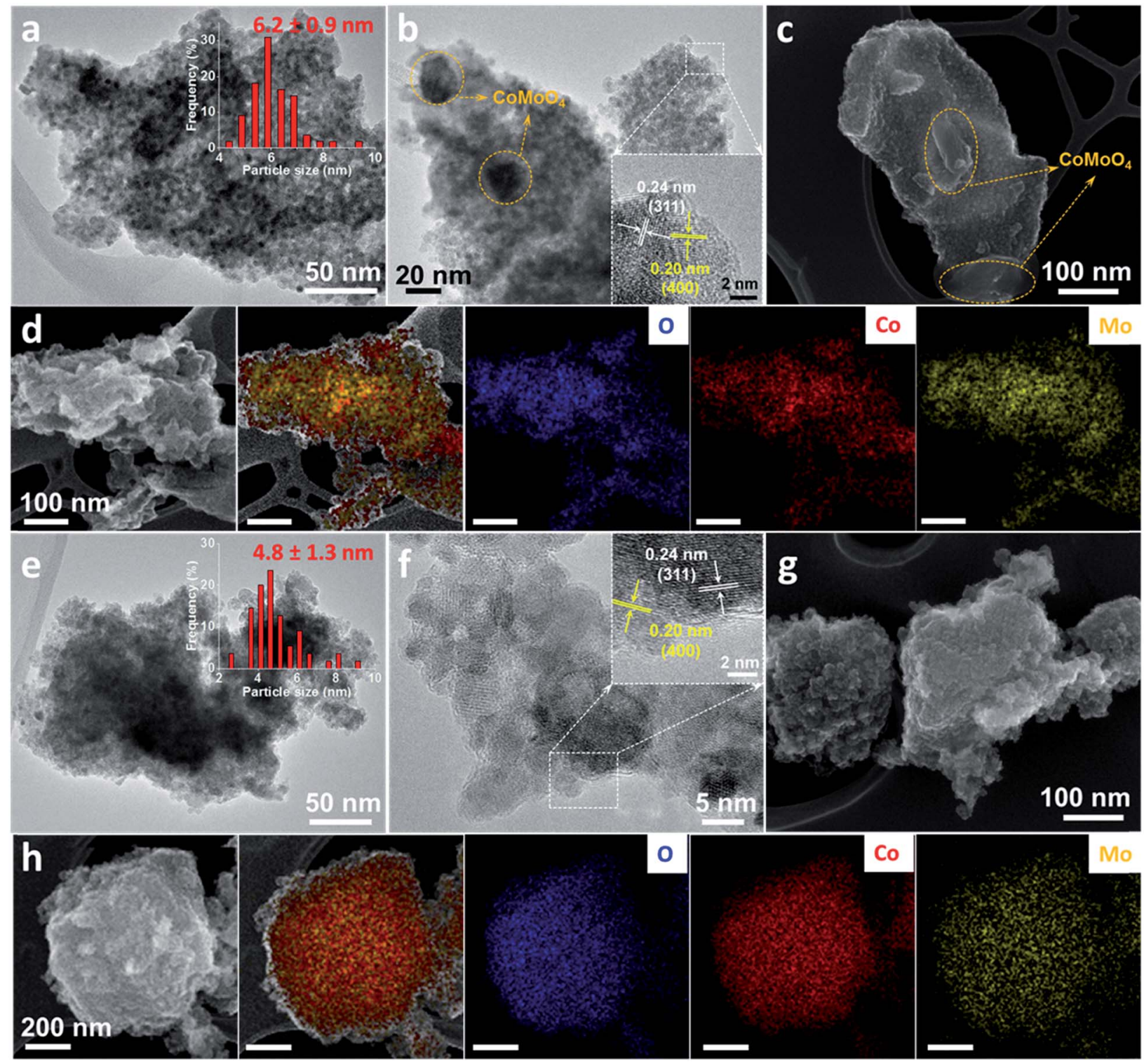

Fig. 3 High resolution TEM images (a and b), dark field HR-SEM image (c), HR-SEM and the corresponding elemental mapping images (d) of the pristine $\mathrm{CO}_{4} \mathrm{Mo}$ oxide. High resolution TEM images (e and f), dark field HR-SEM image (g), HR-SEM and the corresponding elemental mapping images (h) of $\mathrm{CO}_{4} \mathrm{Mo}$ oxides after the leaching process in $0.1 \mathrm{M} \mathrm{HCl}$ solution for $2 \mathrm{~h}$. The marked circles (orange color) in (b) and (c) represent the $\mathrm{CoMoO}_{4}$ particles embedded in the matrix of $\mathrm{CO}_{3} \mathrm{O}_{4}$. Insets in (a) and (e) show the corresponding particle size distribution. Insets in (b) and (f) are the corresponding close-up of the marked rectangles (white color). 
also seen for these nanoparticles (inset of Fig. 3f). This observation is supported by the absence of the $\mathrm{CoMoO}_{4}$ phase in the XRD patterns. The SEM-EDX mapping revealed that Co, Mo, and $\mathrm{O}$ elements were not localized, but homogeneously dispersed over the entire region. The residual Mo species in leached oxides were possibly trapped within the $\mathrm{Co}_{3} \mathrm{O}_{4}$ framework, which protected them from the etching solution. An overview image and EDX mapping of leached samples showed that the leached sample contained only around 2 atomic percent Mo (Fig. S8†), which is not detectable by XRD. The second change is the decrease in the particle size of the leached $\mathrm{Co}_{4} \mathrm{Mo}$ oxide, where the average particle size of $\mathrm{Co}_{3} \mathrm{O}_{4}$ particles decreased from $6.2 \mathrm{~nm}$ to $4.8 \mathrm{~nm}$ after leaching in $\mathrm{HCl}$ solution. Both interparticle voids resulting from the removal of $\mathrm{CoMoO}_{4}$ and the formation of sub- $5 \mathrm{~nm} \mathrm{Co} \mathrm{CO}_{4}$ particles contribute to a threefold enhancement of the SSA of acid-leached $\mathrm{Co}_{4} \mathrm{Mo}$ oxide to $150 \mathrm{~m}^{2} \mathrm{~g}^{-1}$.

X-ray photoelectron spectroscopy (XPS) was further conducted to study the changes in the surface electronic structure of $\mathrm{Co}_{4} \mathrm{Mo}$ oxides after hydrochloride acid leaching. In the highresolution Co $2 \mathrm{p}$ XPS spectra (Fig. S9a and $\mathrm{b} \dagger$ ), characteristic peaks of $\mathrm{Co}^{2+}$ and $\mathrm{Co}^{3+}$ were fitted to the Co $2 \mathrm{p}_{3 / 2}$ and Co $2 \mathrm{p}_{1 / 2}$ peaks of the $\mathrm{Co}_{4} \mathrm{Mo}$ oxide before and after acid leaching: ${ }^{16,38} \mathrm{~A}$ significant difference is that the acid-leached oxide possessed an increased ratio of $\mathrm{Co}^{3+} / \mathrm{Co}^{2+}$ on the surface, as the peaks ascribed to $\mathrm{Co}^{3+}$ became dominant in the Co $2 \mathrm{p}_{3 / 2}$ and Co $2 \mathrm{p}_{1 / 2}$ spectra compared with those of the un-leached sample. This supports the fact that the leaching treatment selectively removed the $\mathrm{CoMoO}_{4}$ phase, leading to a higher ratio of $\mathrm{Co}^{3+} /$ $\mathrm{Co}^{2+}$ on the surface. For the Mo $3 \mathrm{~d}$ region (Fig. S9c and $\mathrm{d} \dagger$ ), the spectra comprise two regions assigned to Mo $3 d_{3 / 2}$ and Mo $3 d_{5 / 2}$ spin-orbit levels of $\mathrm{Mo}^{6+}$ species, suggesting that the Mo element exists in its highest valence state on the surface of the $\mathrm{Co}_{4} \mathrm{Mo}$ oxide. ${ }^{47}$

In order to study the effect of various leaching conditions to optimize the leaching process, additional experiments were carried out by varying the leaching parameters, e.g. acid concentration and leaching time. A large batch of CW-templated $\mathrm{Co}_{4} \mathrm{Mo}$ oxides was first prepared and employed as a starting material for the acid leaching process. A mixed-phase of $\mathrm{Co}_{3} \mathrm{O}_{4}$ and $\mathrm{CoMoO}_{4}$ was detected from XRD patterns where a higher ratio of the $\mathrm{CoMoO}_{4}$ phase was obtained in comparison with the previous small batch synthesis (Fig. S10a†). As discussed above, the incorporation of $\mathrm{CoMoO}_{4}$ with larger particle size decreases the SSA of mixed oxides, and this is supported by a smaller BET surface area of $27 \mathrm{~m}^{2} \mathrm{~g}^{-1}$ (Fig. S10b $\dagger$ ). The concentration of the acid leaching solution was first optimized with the same leaching time $(2 \mathrm{~h})$. As shown in Fig. S11, $\dagger 2 \mathrm{~h}$ of leaching with $0.01 \mathrm{M} \mathrm{HCl}$ solution is not capable of completely removing the $\mathrm{CoMoO}_{4}$ phase. A significant amount of Mo as well as trace impurities remained within the samples (Table $\mathrm{S} 3 \dagger$ ). Upon increasing the acid concentration from 0.05 to 0.2 $\mathrm{M}$, the leached oxides showed a pure phase of $\mathrm{Co}_{3} \mathrm{O}_{4}$ (Fig. S13 $\dagger$ ). The EDX results also confirm the effective removal of Mo species and trace impurities (Fig. S11 $\dagger$ ). Accordingly, a threefold enhancement of SSAs $\left(\sim 100 \mathrm{~m}^{2} \mathrm{~g}^{-1}\right)$ was achieved with a high concentration of $\mathrm{HCl}$ solution, much higher than that of the samples after leaching with $0.01 \mathrm{M} \mathrm{HCl}\left(59 \mathrm{~m}^{2} \mathrm{~g}^{-1}\right.$, Fig. S14 and Table S3 $\dagger$ ). It should be mentioned that $0.2 \mathrm{M} \mathrm{HCl}$ solution was able to etch out the $\mathrm{Co}_{3} \mathrm{O}_{4}$ phase as well since more than $60 \%$ of the weight was lost during the leaching process.

To optimize the leaching time, the concentration of the $\mathrm{HCl}$ solution was fixed at $0.05 \mathrm{M}$, and the leaching time was varied. Five minutes leaching time was already sufficient to leach out the $\mathrm{CoMoO}_{4}$ phase and results in a threefold increase of the SSA of the oxide (Fig. S12-S14 $\dagger$ ). With prolonged leaching time from $30 \mathrm{~min}$ to $6 \mathrm{~h}$, a slight increase of the SSA was obtained (Table $\mathrm{S} 4 \dagger)$. For large practical applications, it is essential to operate the process under mild conditions in terms of safety and production cost. Hereby, we optimized the leaching process by utilizing $0.05 \mathrm{M} \mathrm{HCl}$ aqueous solution for only $30 \mathrm{~min}$ of leaching. This simple two-step process shows great potential for practical production of high surface area cobalt oxides.

After a detailed structural analysis, the electrocatalytic properties towards the OER were evaluated in $1 \mathrm{M} \mathrm{KOH}$ by loading the catalysts on the glassy carbon electrode, following the protocol proposed by the Jaramillo group. ${ }^{10}$ Fig. $4 \mathrm{a}$ and b depict the linear scanning voltammetry (LSV) curves of $\mathrm{Co}_{3} \mathrm{O}_{4}$ and Co-Mo oxides before and after the acid leaching process (0.1 $\mathrm{M} \mathrm{HCl}$ solution for $2 \mathrm{~h}$ ), respectively. In comparison with pristine $\mathrm{Co}_{3} \mathrm{O}_{4}$, the mixed oxides were more efficient in a low potential region (below $1.65 \mathrm{~V}_{\mathrm{RHE}}$ ), requiring a smaller overpotential to reach a current density of $10 \mathrm{~mA} \mathrm{~cm}^{-2}$ (Table S5 $\dagger$ ). With increasing applied potential, $\mathrm{Co}_{3} \mathrm{O}_{4}$ became more active towards the OER by delivering a higher catalytic current. This is attributed to the lower Tafel slope of pure $\mathrm{Co}_{3} \mathrm{O}_{4}$ than the mixed oxides (inset of Fig. $4 \mathrm{a}$ and Table $\mathrm{S} 5 \dagger$ ).

Upon leaching with $0.1 \mathrm{M} \mathrm{HCl}$ solution, the Co-Mo oxides exhibited superior OER activity to $\mathrm{Co}_{3} \mathrm{O}_{4}$ in the whole applied potential region. For all mixed oxides, the overpotential to reach $10 \mathrm{~mA} \mathrm{~cm}{ }^{-2}$ was significantly decreased. It has been reported that the incorporation of Mo could activate the cobalt-based catalyst by modulating the electronic structure of cobalt to achieve the optimized adsorption energy for the reaction intermediates. ${ }^{\mathbf{4 8 , 4 9}}$ An in situ X-ray adsorption study on the CoMo based electrocatalyst confirmed the changes of valence states of Co and Mo elements. When a potential of $1.4 \mathrm{~V}_{\mathrm{RHE}}$ is applied, the oxidation state of Mo decreased while Co was readily oxidized to a higher valence, similar to that of active $\mathrm{CoOOH}$ species. ${ }^{48}$ In addition, porous $\mathrm{CoMoO}_{4}$ has been reported to be an efficient OER catalyst. ${ }^{47}$ These could explain the catalytic performance enhancements of mixed Co-Mo oxides compared to $\mathrm{Co}_{3} \mathrm{O}_{4}$. As is expected, a decrease was also observed for Tafel slopes of mixed oxides upon the acid leaching process (inset of Fig. 4a and b). Among the leached oxides, the highest OER activity was achieved with the $\mathrm{Co}_{4} \mathrm{Mo}$ oxide that has the highest SSA. At an applied potential of $1.7 \mathrm{~V}_{\mathrm{RHE}}$, the acidleached $\mathrm{Co}_{4} \mathrm{Mo}$ oxide catalyst achieved a current density of 123 $\mathrm{mA} \mathrm{cm}{ }^{-2}$, outperforming the benchmark ordered mesoporous $\mathrm{Co}_{3} \mathrm{O}_{4}\left(\sim 105 \mathrm{~mA} \mathrm{~cm}^{-2}\right) .{ }^{50}$

In order to compare the OER activity of pristine oxides and acid-leached oxides, the current densities at $1.7 \mathrm{~V}_{\mathrm{RHE}}$ and the overpotential to reach $10 \mathrm{~mA} \mathrm{~cm}^{-2}$ are summarized in Fig. 4c. A significant enhancement was seen for the current densities of 

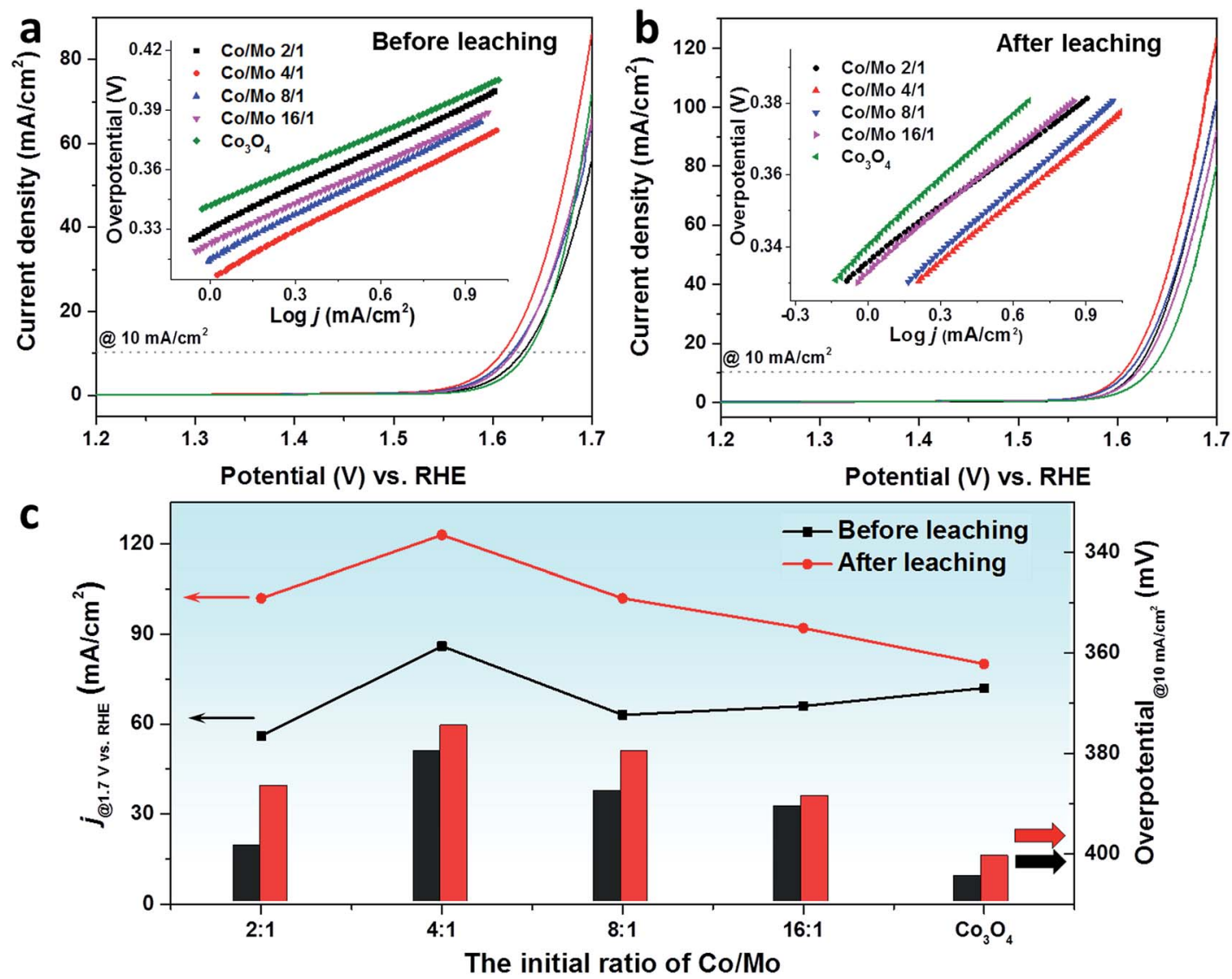

Fig. 4 The LSV curves of CW-templated $\mathrm{Co}-\mathrm{Mo}$ oxides and $\mathrm{CO}_{3} \mathrm{O}_{4}$ before (a) and after (b) leaching in $0.1 \mathrm{M} \mathrm{HCl} \mathrm{solution} \mathrm{for} 2 \mathrm{~h}$. Insets in (a) and (b) show the corresponding Tafel plots. (c) A comparison on the current density at $1.7 \mathrm{~V}_{\mathrm{RHE}}$ (lines, left axis) and the overpotential at $10 \mathrm{~mA} \mathrm{~cm}^{-2}$ (columns, right axis) of the oxides before and after acid leaching.

all leached oxides, especially for the Co-Mo oxides. This escalation is mainly related to the change of the SSA where Co-Mo oxides show a more pronounced increase of the SSA compared to pure $\mathrm{Co}_{3} \mathrm{O}_{4}$. The other key parameter to determine OER activity, i.e. the overpotential to reach a current density of $10 \mathrm{~mA}$ $\mathrm{cm}^{-2}$, shows an opposite trend, where a drop was observed due to acid leaching. A much smaller overpotential was required to deliver a current density of $10 \mathrm{~mA} \mathrm{~cm}{ }^{-2}$ for Co-Mo oxides. In addition to the remaining Mo which could act as the active species for leached Co-Mo oxides, the removal of the $\mathrm{CoMoO}_{4}$ phase could create some defects within the structure which results in the superior OER activity. ${ }^{33,51}$

Electrochemical impedance spectroscopy (EIS) test was performed to assess the charge transfer properties of $\mathrm{Co}_{3} \mathrm{O}_{4}$ and $\mathrm{Co}_{4} \mathrm{Mo}$ oxides. Fig. 5 depicts the Nyquist plots measured at 1.6 $\mathrm{V}_{\mathrm{RHE}}$, from which the corresponding resistances were obtained according to the Randle model (Fig. S15 $\dagger$ ). ${ }^{52}$ The resistance in the high-frequency region is $\sim 6 \mathrm{ohm}$ for all oxides, which is related to the solution resistance of the electrochemical setup. According to the diameter of the semicircles in the lowfrequency region, pristine $\mathrm{Co}_{3} \mathrm{O}_{4}$ showed the highest charge transfer resistance $\left(R_{\mathrm{ct}}\right)$. A much lower $R_{\mathrm{ct}}$ was determined for $\mathrm{Co}_{4} \mathrm{Mo}$ oxides, indicating that the incorporation of Mo could improve the charge transfer ability of the cobalt oxide electrocatalyst. Transferring electrons faster on the pristine $\mathrm{Co}_{4} \mathrm{Mo}$ oxide contributes to a higher rate of OER activity in comparison with the pristine $\mathrm{Co}_{3} \mathrm{O}_{4}$ electrocatalyst. After the acid leaching process, both oxides showed reduced $R_{\mathrm{ct}}$, which

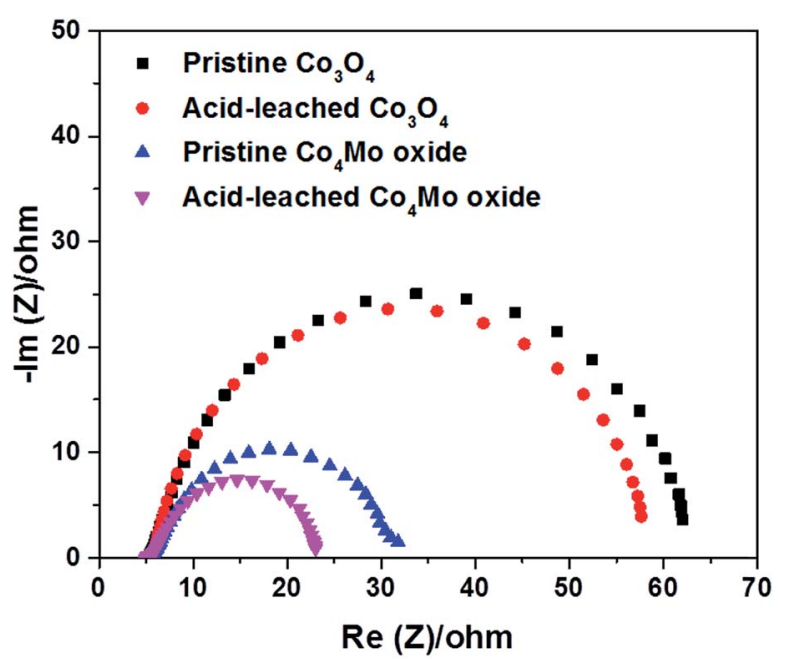

Fig. 5 The Nyquist plots of pristine and acid-leached $\mathrm{CO}_{3} \mathrm{O}_{4}$ and $\mathrm{Co}_{4} \mathrm{Mo}$ oxides in $0.1 \mathrm{M} \mathrm{HCl}$ solution for $2 \mathrm{~h}$. 
suggests that such a leaching process leads to an enhancement of oxygen evolution kinetics of electrocatalysts. Additionally, we measured the double-layer capacitance $\left(C_{\mathrm{dl}}\right)$ using a simple CV method in a non-faradaic potential range to estimate the electrochemically active surface area (ECSA). As shown in Fig. S16, $\dagger$ the acid leached $\mathrm{Co}_{4} \mathrm{Mo}$ oxide possesses a higher $C_{\mathrm{dl}}(0.65 \mathrm{mF})$ compared to the unleached oxide $(0.47 \mathrm{mF})$. Accordingly, a larger ECSA was exhibited on the $\mathrm{Co}_{4} \mathrm{Mo}$ oxide after leaching, suggesting that the acid-leached oxide provided more active sites exposed to the reactants in the $1 \mathrm{M} \mathrm{KOH}$ electrolyte for the OER.

Furthermore, a stability study was carried out by a chronopotentiometric test at a constant current density of $10 \mathrm{~mA}$ $\mathrm{cm}^{-2}$. The long-term stability test that was conducted with the rotating disk electrode shows significant catalyst detachment after $3 \mathrm{~h}$ under the applied bias. However, we could overcome this detachment issue by depositing the sample on carbon fiber paper to be employed as the anode. As seen in Fig. S17, $\uparrow$ no significant change was observed in the required potential for the acid-leached $\mathrm{Co}_{4} \mathrm{Mo}$ oxide to keep delivering the catalytic current for $12 \mathrm{~h}$, proving the long-term stability of the acidleached $\mathrm{Co}_{4}$ Mo oxide.

In order to demonstrate the general applicability of this selective acid-leaching strategy, three other earth-abundant metals were selected and incorporated into the $\mathrm{Co}_{4} \mathrm{M}$ oxides $(\mathrm{M}$ $=\mathrm{Li}, \mathrm{Mg}$, and $\mathrm{Ca}$ ). After the same leaching process, M-containing species were selectively washed out, as confirmed by the elemental analysis from EDX results (Fig. S18, S19 and Table $\left.\mathrm{S} 6{ }^{\dagger}\right)$. The XRD results demonstrate a pure $\mathrm{Co}_{3} \mathrm{O}_{4}$ phase after the leaching process (Fig. S20†). Unlike the $\beta-\mathrm{CoMoO}_{4}$ phase with an open and defective structure, it has been shown that the wellcrystalline structure of $\mathrm{LiCoO}_{2}$ and $\mathrm{CaCO}_{3}$ can be formed at milder temperatures. ${ }^{53,54}$ Thus, the crystal structure may not be the reason causing the selective leaching of these M-containing phases. Instead, their inferior stability in acidic solution could be explained by the basic tendency of these metals in the oxide form which contributes to the fast dissolution of M-containing phases even in diluted acid solution..$^{54-56}$

HR-TEM images of these leached oxides were also taken, where similar nanostructures consisting of small crystalline particles were revealed (Fig. 6a-c). The enlarged images of isolated particles exhibited clear lattice fringes with a spacing of $0.24 \mathrm{~nm}$, attributed to the (311) plane of the $\mathrm{Co}_{3} \mathrm{O}_{4}$ spinel. A distinct difference is that after acid leaching, the $\mathrm{Co}_{4} \mathrm{Li}$ oxide possessed larger particles compared to the oxides incorporated with $\mathrm{Mg}$ and $\mathrm{Ca}$. Similarly, a significant change was exhibited in the textural parameters of these acid-leached oxides (Fig. S21 †). In particular, a three-fold increase was seen in the SSA of $\mathrm{Co}_{4} \mathrm{Mg}$ and $\mathrm{Co}_{4} \mathrm{Ca}$ oxides prepared from this acid-leaching strategy (Fig. 6d), which is even higher than the SSA of metal oxides that are prepared via nanocasting by using ordered mesoporous silica as the template. ${ }^{16}$ Upon employing these oxides as OER electrocatalysts, a clear enhancement was seen in the catalytic performance of the oxides after the leaching process (Fig. S22 $\dagger$ and 6e). It should be mentioned that $\mathrm{Mg}$ and $\mathrm{Ca}$ are among the most abundant metals and are cost-effective, which can be employed for large scale surfactant-free nanoparticle synthesis for diverse applications.

In addition, this selective acid-leaching strategy can be extended to synthesis of other transition metal oxides like $\mathrm{Fe}_{2} \mathrm{O}_{3}$
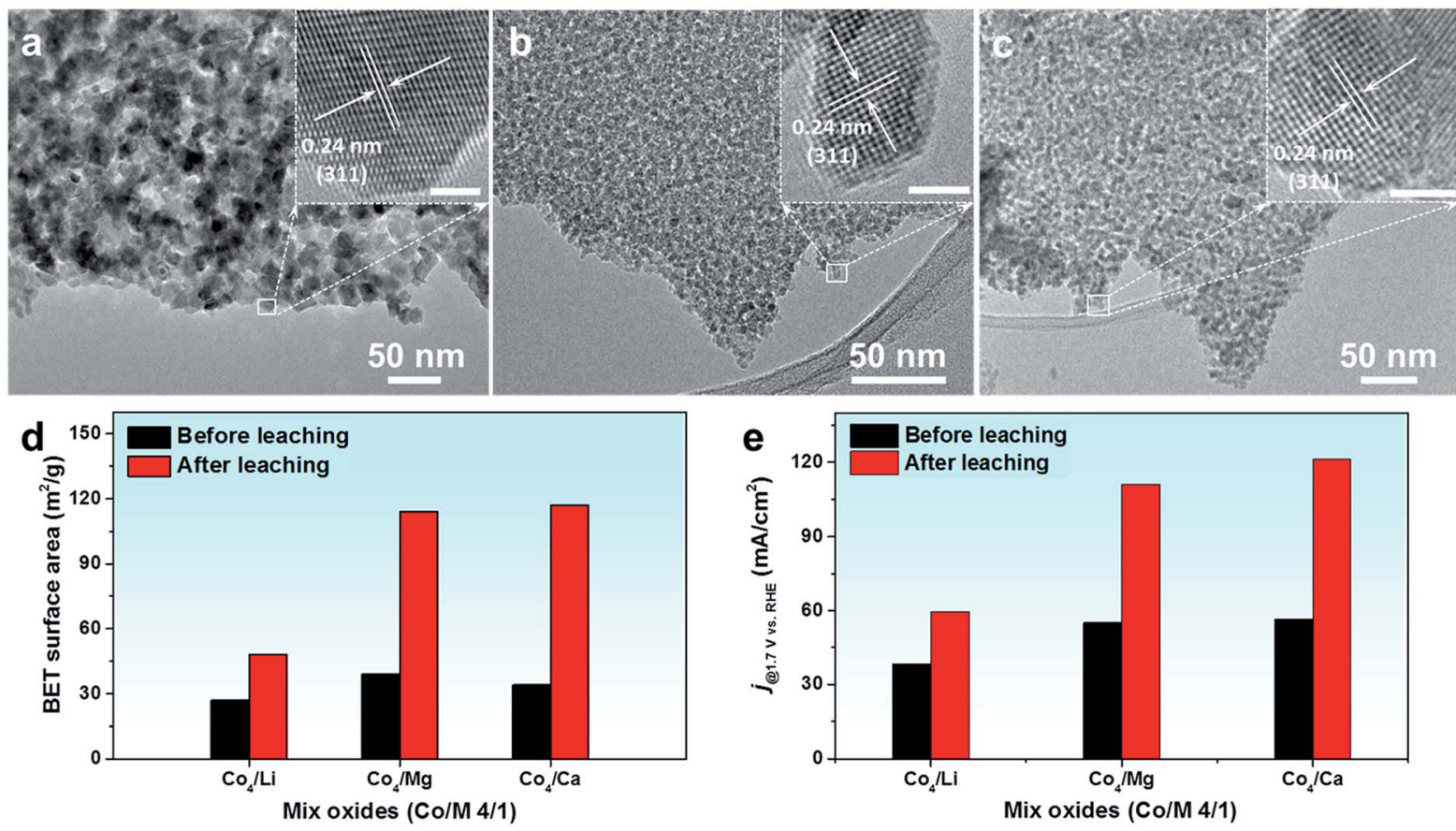

Fig. 6 (a-c) HR-TEM images of the acid-leached $\mathrm{CO}_{4} \mathrm{Li}$ oxide, $\mathrm{CO}_{4} \mathrm{Mg}$ oxide, and $\mathrm{CO}_{4} \mathrm{Ca}$ oxide, respectively. Summarized values of (d) BET surface area and (e) current density at $1.7 \mathrm{~V}_{\mathrm{RHE}}$ of $\mathrm{CW}$-templated $\mathrm{CO}_{4} \mathrm{M}$ oxides $(\mathrm{M}=\mathrm{Li}, \mathrm{Mg}$, and $\mathrm{Ca}$ ) before and after leaching in $0.1 \mathrm{M} \mathrm{HCl}$ solution for $2 \mathrm{~h}$. 
and NiO. An acid-leaching process selectively removed Ca from $\mathrm{Ni}_{4} \mathrm{Ca}$ oxide and $\mathrm{Fe}_{4} \mathrm{Ca}$ oxide (Fig. S23, S24 and Table S7†). As a result of phase purification due to acid-leaching, a pure phase of $\mathrm{Fe}_{2} \mathrm{O}_{3}$ and $\mathrm{NiO}$ was prepared with a high specific surface area of up to $150 \mathrm{~m}^{2} \mathrm{~g}^{-1}$ (Fig. S25 and S26 $\dagger$ ).

\section{Conclusions}

In summary, we reported a general and facile acid-leaching process to engineer $\mathrm{Co}_{3} \mathrm{O}_{4}$ nanostructures for the electrocatalytic oxygen evolution reaction. Through a scalable coffeewaste templating method, Co-Mo oxides were prepared with mixed phases of $\mathrm{Co}_{3} \mathrm{O}_{4}$ and $\mathrm{CoMoO}_{4}$. The $\mathrm{CoMoO}_{4}$ phase was selectively leached out by treating the oxides with diluted $\mathrm{HCl}$ solution, resulting in the formation of sub-5 $\mathrm{nm}$ particles with a pure $\mathrm{Co}_{3} \mathrm{O}_{4}$ phase and a threefold increase of the specific surface area (up to $150 \mathrm{~m}^{2} \mathrm{~g}^{-1}$ ). Electrochemical measurements revealed that the acid-leached oxides exhibit superior catalytic activity to pristine oxides, which is attributed to (i) a larger surface area, (ii) phase purification to expose more active $\mathrm{Co}_{3} \mathrm{O}_{4}$ species to the reactant, and (iii) faster charge transfer kinetics for the OER. This strategy has widespread applicability through selectively leaching earth-abundant metals. $\mathrm{Li}, \mathrm{Mg}$ and $\mathrm{Ca}$ species can be used for the acid-leaching process because of the resulting high surface area cobalt oxide nanocrystals. Moreover, this acid-leaching strategy can be extended to the synthesis of other metal oxides such as $\mathrm{Fe}_{2} \mathrm{O}_{3}$ and $\mathrm{NiO}$ with high surface areas of up to $150 \mathrm{~m}^{2} \mathrm{~g}^{-1}$. The developed process does not require harsh conditions, expensive chemicals, dedicated instruments or time-consuming operation and it can be applied to prepare nanocrystals at the industrial scale.

\section{Conflicts of interest}

There are no conflicts to declare.

\section{Acknowledgements}

This work is financially supported by IMPRS-RECHARGE and MAXNET Energy consortium of Max Planck Society. We thank S. Palm, H. Bongard, A. Kostis, and A. Schlüter for EDX analysis and microscopy images and A. Bähr for proofreading. We would also thank J. N. Büscher and PD Dr C. Weidenthaler for XPS measurements and related discussions. The manuscript is dedicated to the memory of Prof. Dr Walter Thiel who recently passed away.

\section{Notes and references}

1 N. S. Lewis and D. G. Nocera, Proc. Natl. Acad. Sci. U. S. A., 2006, 103, 15729-15735.

2 S. Chu, Y. Cui and N. Liu, Nat. Mater., 2017, 16, 16-22. 3 L. Schlapbach and A. Züttel, Nature, 2001, 414, 353-358. 4 X. Deng, K. Chen and H. Tüysüz, Chem. Mater., 2017, 29, 4052.
5 M. G. Walter, E. L. Warren, J. R. McKone, S. W. Boettcher, Q. Mi, E. A. Santori and N. S. Lewis, Chem. Rev., 2010, 110, 6446-6473.

6 B. M. Hunter, H. B. Gray and A. M. Müller, Chem. Rev., 2016, 116, 14120-14136.

7 F. Song, L. Bai, A. Moysiadou, S. Lee, C. Hu, L. Liardet and X. Hu, J. Am. Chem. Soc., 2018, 140, 7748-7759.

8 N.-T. Suen, S.-F. Hung, Q. Quan, N. Zhang, Y.-J. Xu and H. M. Chen, Chem. Soc. Rev., 2017, 46, 337-365.

9 F. Lyu, Y. Bai, Z. Li, W. Xu, Q. Wang, J. Mao, L. Wang, X. Zhang and Y. Yin, Adv. Funct. Mater., 2017, 27, 1702324.

10 C. C. L. McCrory, S. Jung, I. M. Ferrer, S. M. Chatman, J. C. Peters and T. F. Jaramillo, J. Am. Chem. Soc., 2015, 137, 4347-4357.

11 G. P. Gardner, Y. B. Go, D. M. Robinson, P. F. Smith, J. Hadermann, A. Abakumov, M. Greenblatt and G. C. Dismukes, Angew. Chem., Int. Ed., 2012, 51, 1616-1619.

12 R. Kötz, H. J. Lewerenz and S. Stucki, J. Electrochem. Soc., 1983, 130, 825-829.

13 E. Antolini, ACS Catal., 2014, 4, 1426-1440.

14 I. Roger, M. A. Shipman and M. D. Symes, Nat. Rev. Chem., 2017, 1, 0003.

15 H. S. Ahn and T. D. Tilley, Adv. Funct. Mater., 2013, 23, 227233.

16 T. Grewe, X. Deng, C. Weidenthaler, F. Schüth and H. Tüysüz, Chem. Mater., 2013, 25, 4926-4935.

17 M. S. Burke, L. J. Enman, A. S. Batchellor, S. Zou and S. W. Boettcher, Chem. Mater., 2015, 27, 7549-7558.

18 F. Dionigi and P. Strasser, Adv. Energy Mater., 2016, 6, 1600621.

19 M. Gong, Y. Li, H. Wang, Y. Liang, J. Z. Wu, J. Zhou, J. Wang, T. Regier, F. Wei and H. Dai, J. Am. Chem. Soc., 2013, 135, 8452-8455.

20 F. Song and X. Hu, J. Am. Chem. Soc., 2014, 136, 1648116484.

21 G.-h. Moon, M. Yu, C. K. Chan and H. Tüysüz, Angew. Chem., Int. Ed., 2019, 58, 3491-3495.

22 Q. Fu, T. Wu, G. Fu, T. Gao, J. Han, T. Yao, Y. Zhang, W. Zhong, X. Wang and B. Song, ACS Energy Lett., 2018, 3, 1744-1752.

23 P. W. Menezes, A. Indra, I. Zaharieva, C. Walter, S. Loos, S. Hoffmann, R. Schlögl, H. Dau and M. Driess, Energy Environ. Sci., 2019, 12, 988-999.

24 D. Li, H. Baydoun, B. Kulikowski and S. L. Brock, Chem. Mater., 2017, 29, 3048-3054.

25 L. Yan, L. Cao, P. Dai, X. Gu, D. Liu, L. Li, Y. Wang and X. Zhao, Adv. Funct. Mater., 2017, 27, 1703455.

26 J. Masa, P. Weide, D. Peeters, I. Sinev, W. Xia, Z. Sun, C. Somsen, M. Muhler and W. Schuhmann, Adv. Energy Mater., 2016, 6, 1502313.

27 P. Chen, K. Xu, T. Zhou, Y. Tong, J. Wu, H. Cheng, X. Lu, H. Ding, C. Wu and Y. Xie, Angew. Chem., Int. Ed., 2016, 55, 2488-2492.

28 J. Suntivich, K. J. May, H. A. Gasteiger, J. B. Goodenough and Y. Shao-Horn, Science, 2011, 334, 1383-1385. 
29 B. Zhao, L. Zhang, D. Zhen, S. Yoo, Y. Ding, D. Chen, Y. Chen, Q. Zhang, B. Doyle, X. Xiong and M. Liu, Nat. Commun., 2017, 8, 14586.

30 A. J. Esswein, M. J. McMurdo, P. N. Ross, A. T. Bell and T. D. Tilley, J. Phys. Chem. C, 2009, 113, 15068-15072.

31 A. Bergmann, E. Martinez-Moreno, D. Teschner, P. Chernev, M. Gliech, J. F. de Araujo, T. Reier, H. Dau and P. Strasser, Nat. Commun., 2015, 6, 8625.

32 C. Zhang, M. Antonietti and T.-P. Fellinger, Adv. Funct. Mater., 2014, 24, 7655-7665.

33 J. Rosen, G. S. Hutchings and F. Jiao, J. Am. Chem. Soc., 2013, 135, 4516-4521.

34 X. Deng and H. Tüysüz, ACS Catal., 2014, 4, 3701-3714.

35 J. Wang, W. Cui, Q. Liu, Z. Xing, A. M. Asiri and X. Sun, Adv. Mater., 2016, 28, 215-230.

36 X. Deng, W. N. Schmidt and H. Tüysüz, Chem. Mater., 2014, 26, 6127-6134.

37 J. D. Blakemore, H. B. Gray, J. R. Winkler and A. M. Müller, ACS Catal., 2013, 3, 2497-2500.

38 Y. Zhou, C.-K. Dong, L. L. Han, J. Yang and X.-W. Du, ACS Catal., 2016, 6, 6699-6703.

39 M. Yu, C. K. Chan and H. Tüysüz, ChemSusChem, 2018, 11, 605-611.

40 D. Zagorac, J. C. Schön, M. Rosić, J. Zagorac, D. Jordanov, J. Luković and B. Matović, Chem. Mater., 2017, 52, 1700069.

41 D. Vie, E. Martínez, F. Sapiña, J.-V. Folgado, A. Beltrán, R. X. Valenzuela and V. Cortés-Corberán, Chem. Mater., 2004, 16, 1697-1703.

42 J. A. Rodriguez, S. Chaturvedi, J. C. Hanson and J. L. Brito, J. Phys. Chem. B, 1999, 103, 770-781.
43 G. Li, C. Zhang, Z. Wang, H. Huang, H. Peng and X. Li, Appl. Catal., A, 2018, 550, 67-76.

44 S. Kendell and T. Brown, React. Kinet., Mech. Catal., 2010, 99, 251-268.

45 C. Rocchiccioli-Deltcheff, A. Aouissi, M. M. Bettahar, S. Launay and M. Fournier, J. Catal., 1996, 164, 16-27.

46 A. Rumplecker, F. Kleitz, E.-L. Salabas and F. Schüth, Chem. Mater., 2007, 19, 485-496.

47 M. Q. Yu, L. X. Jiang and H. G. Yang, Chem. Commun., 2015, 51, 14361-14364.

48 P. Liu, S. Yang, L. Zheng, B. Zhang and H. Yang, Chem. Sci., 2017, 8, 3484-3488.

49 S. Hao, L. Chen, C. Yu, B. Yang, Z. Li, Y. Hou, L. Lei and X. Zhang, ACS Energy Lett., 2019, 9, 952-959.

50 X. Deng, S. Öztürk, C. Weidenthaler and H. Tüysüz, ACS Appl. Mater. Interfaces, 2017, 9, 21225-21233.

51 S. Wahl, S. M. El-Refaei, A. G. Buzanich, P. Amsalem, K.-S. Lee, N. Koch, M.-L. Doublet and N. Pinna, Adv. Energy Mater., 2019, 9, 1900328.

52 C. C. L. McCrory, S. Jung, J. C. Peters and T. F. Jaramillo, J. Am. Chem. Soc., 2013, 135, 16977-16987.

53 E. Rossen, J. N. Reimers and J. R. Dahn, Solid State Ionics, 1993, 62, 53-60.

54 H. Zhu, Z. Liu, Y. Wang, D. Kong, X. Yuan and Z. Xie, Chem. Mater., 2008, 20, 1134-1139.

55 A. Auroux and A. Gervasini, J. Phys. Chem., 1990, 94, 63716379.

56 D. F. Shriver, Acc. Chem. Res., 1970, 3, 231-238. 